\title{
Research on the Communication Mode of Shanxi Red Cultural Creative Tourism under the Background of Interactive Image Design
}

\author{
Kun $\operatorname{Tian}^{1}$, Jian $\mathrm{Li}^{1}$, Jiang Chen ${ }^{2}$ \\ ${ }^{1}$ Communication University of Shanxi, Taiyuan, China \\ ${ }^{2}$ The Guangzhou Academy of Fine Arts, Guangzhou, China
}

\begin{abstract}
With the advent of the Internet era and the popularization of computer intelligent software and hardware, the textual information we are exposed to is declining. Humans have slowly moved from obtaining information through text to understanding the world in a multidimensional space of images, sounds and perception. In the context of the visual age, as a brand-new design language, digital images have a more powerful evocative ability than a simple combination of text and pictures. With the maturity of digital technology and the improvement of the public's aesthetic level, people are no longer satisfied with the audience role of passively receiving information, but are eager to become information disseminators while obtaining information through participation and interaction. Due to the public's pursuit of information acquisition, the interactive design function of digital images has received more and more attention and has been widely used in various fields of information dissemination. As a new type of media, digital images have sprung up in mass communication by virtue of their unique advantages and become an irreplaceable part. The rise of digital images has opened up new channels for the spread of Shanxi's red culture. This article will take the advantages of interactive video media as the breakthrough point, analyze the current problems in the use of interactive images in the communication of Shanxi's red culture, and put forward practical suggestions on how to apply digital images to the communication of Shanxi's red culture, with a view to enhancing Shanxi's red The spread of culture.
\end{abstract}

\section{INTRODUCTION}

Digital interactive images are currently used in space in two forms of expression. One is based on interactive projection technology, somatosensory recognition technology and actors in the space to produce real-time interaction, interactive projection is a new type of multimedia display technology, using advanced computer vision technology and Projection display technology to create a fantasy interactive experience [1]. The second is to dynamically interact with the actors in the produced video. This kind of interaction is designed in advance by the technicians based on the actor's actions. If the space is compared to a "box", the actors and props are the "items in the box", then digital interactive images It is "wrapping paper" that extends the space of the box. This is because of its own multi-dimensional properties such as twodimensional and three-dimensional, which makes the space multidimensional and three-dimensional. At the same time, the progress of interactive projection technology has changed the form of creation. From traditional physical scenes to images that change at any time, interactive images are virtual and dramatic, carrying the role of spreading spirit, emotion and content. Creators should not only use images to express the reality of reality, but also pay attention to the medium itself. The changes in the viewing mode brought about.

\section{OVERVIEW OF INTERACTIVE DIGITAL IMAGES}

American computer scientist Nicholas Negroponte believes that "digitalization will become the characteristic and basic driving force of development in this era, and digital survival will become the basic way of human survival in the digital era." The emergence of the Internet is a sign of the digital age, although digital imaging technology is now It has only appeared for about forty years, but digital images have flooded every aspect of our modern life. From waking up in the morning to falling asleep at night, all kinds of images appear in every corner of life. Whether watching video advertisements repeatedly played on the bus TV, shopping through mobile phones, or using computers to work and browse the web, people actively or passively accept image information at all times. Digital images play an irreplaceable and important role in people's lives, social progress and information exchange. At the same time, digital imaging technology has had a revolutionary impact on the communication methods of the visual culture industry and the practical methods of 
designers. As information dissemination becomes quickly barrier-free with the development of technology and interactive images, the social roles of designers and audiences have also undergone essential changes. Designers are no longer simply artists who express themselves, but transformed into disseminators of information in an artistic form of production; the realization of interactive technology; enables the audience to participate in interaction and communication in the process of receiving information, and then Become a designer in information dissemination.[2]

\section{INTERACTIVE DIGITAL IMAGE DESIGN}

Interactivity cannot be produced without digital media as a medium. Digital media is integrated and integrates multiple media elements (video, pictures, text, sound, animation, etc.) into one. Through digital media, users can participate in the cyclic process of input (the user changes the content of the message through the medium) and output (the original computer is fed back to the user through the medium), which is called interaction. In the early days of digital media technology, most scholars generally focused on the technical level when studying the interactive features of digital images. Once a certain medium allows the viewer to independently manipulate one or more elements, this medium has interactive value. With the improvement of technology, when we talk about interactivity, the focus is more on the user's participation, that is, to what extent the user's behavior can change the content of the image and the development of the plot. Interactive video, as a new way of dissemination of digital video, breaks the single role that the audience can only serve as the viewer. This direct user intervention makes the content of the image more open, and also changes the relationship between the disseminator and the disseminated in the process of public information dissemination. The audience has the dual identity of the disseminator and the disseminated, breaking the traditional passive receiving position of information, and realizing the equal status of the disseminator in information interaction. This breakthrough has greatly enriched the dissemination of public information and expanded the space for cultural exchanges.[3]

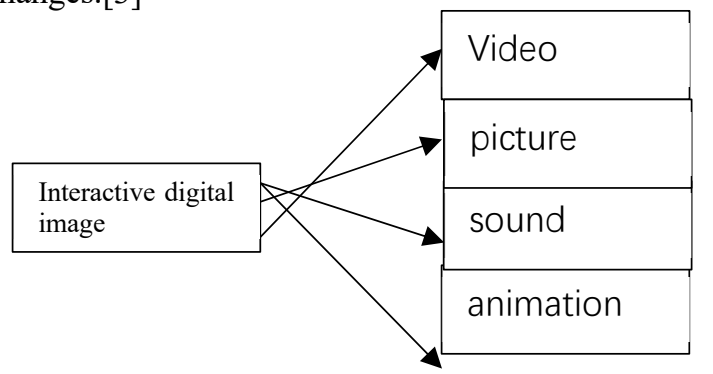

Figure 1. Interactive digital image

\section{THE RATIONAL USE OF INTERACTIVE VIDEO MEDIA IN THE SPREAD OF SHANXI'S RED CULTURE}

In the information age, interactive images, as the most widely used media channel, undoubtedly play an important role in the spread of Shanxi's red culture. Whether the characteristics and laws of interactive video media can be effectively used is related to whether the red culture can be loved and recognized by netizens. In this regard, we should use interactive images as the medium, make full use of various forms of interactive image communication, and combine them with the spread of Shanxi's red culture to open up a new learning position for people to contact and understand Shanxi's red culture.[4]

\subsection{Reasonably construct Shanxi's red website and expand the interactive image position for the spread of Shanxi's red culture}

First of all, under the guidance of correct thinking, open up a Shanxi red website reasonably. Nowadays, Chinese people, especially the new generation of post-90s and post00s, have complex and changeable thinking and eclectic styles of behavior. This requires educators to have a certain grasp of their thinking and behavior dynamics, so as to better put them into practice. practice. In the process of building Shanxi's red website, upper-level departments or media organizations must proceed from reality and under the guidance of correct ideology and theory, create a healthy interactive image environment for netizens, so that Shanxi's red resources can be presented to people more completely.

Second, strengthen the publicity and promotion of Shanxi's red website. Even if the content of a piece of work is very rich, if it is not familiar to the audience, it can only become a form and empty talk, and it will even be swallowed up by other kinds of information. Therefore, departments at all levels in Shanxi Province should strengthen the publicity and promotion of red websites, extensively carry out publicity and introduction activities of Shanxi red culture, attract the attention of netizens, and timely occupy the Internet, a popular interactive image position of red culture. In this regard, red websites can cooperate with mainstream search engines such as Baidu and Google to increase the probability of being searched by people. At the same time, they can establish exchange links with popular websites such as Sina and Sohu as much as possible, or they can borrow newspapers and publicity. Manuals, etc. to promote the Shanxi Red Website.

Third, the planning of the red website must be in line with the actual needs of the audience. The reason why the Internet has become popular all over the world in a short period of time and has attracted the attention of the majority of netizens is inseparable from the fact that it has always been closely connected with people's production and life and taking into account people's real needs. Shanxi is a province with large red resources. It not only contains profound red historical facts, but also has an old revolutionary base with beautiful scenery and pleasant ecology. In recent years, Shanxi's red tourism has flourished, attracting a large number of tourists to come here. Before traveling, many people often need to have a detailed understanding of a series of related issues such as travel routes, ticket prices, and consumption levels. Shanxi Red Website can design some sections and content with service functions in response to this demand of people, 
such as red classic lines, so as to promote the effect of communication.

Finally, the red website should highlight flexibility and novelty in its construction. First, the content of the website should be both pictures and texts, and the presentation of the red culture should be novel and unique. For example, a certain amount of audiovisual materials can be added to the website to make Shanxi's red culture more concrete, or a Shanxi red film and television website can be established specifically to incorporate the film and television resources that previously embody Shanxi's red culture. Second, the information on the red website should be updated in time, and it is necessary to learn to interpret and improve the Shanxi red spirit from a new perspective to enrich the content of the red culture. For example, some deeds of characters that reflect the red spirit can be used as vivid materials to enhance the appeal of red culture.[5]

\subsection{Building an interactive video classroom}

In recent years, interactive video classrooms have gradually entered people's daily lives and become a mainstream trend in learning. Various remote online interactive training videos have also emerged. This type of education breaks the limitations of time and region, improves the convenience and autonomy of netizens in learning, and is catering to the needs of netizens for interpersonal communication. Therefore, the propaganda departments and news media of party committees at all levels in Shanxi can consider including red culture in interactive video classrooms to carry out red education at a deeper level. This undoubtedly plays a very good role in reshaping youths with rebellious thinking. To build a red cultural interactive video classroom, you can hire some experts and scholars with profound theoretical attainments and familiar with local customs and cultures to tell the historical facts of Shanxi's red history and interpret the red spirit of Shanxi in depth through videos; or invite some old people who have personal experience of Shanxi's revolutionary struggle. The Red Army and veteran soldiers recalled the revolutionary stories and struggles of that year.

\subsection{Try to use new forms of interactive images such as Weibo and podcasts}

Blogs, based on the interactive function of the Internet, provide great freedom for the dissemination and communication of red culture. Bloggers can freely upload text, pictures, videos, etc. related to red culture, while other blogs can interact with each other. In contrast, Weibo is more open and can convey the latest developments in a short time and at the fastest speed. Nowadays, many individuals or red culture communication agencies have established Weibo accounts. They release information about red culture at any time and update space dynamics to attract more audiences. "Podcasting" is mainly video and audio. It satisfies the needs of people for self-expression, strengthens the interactive function of interactive images, and is more easily respected by netizens, allowing them to deeply understand the spiritual connotation of red culture in the entertainment and education. [6]
At present, the interactive video dissemination of Shanxi's red culture is mainly limited to official channels such as websites, and has not used new forms such as podcasts, microblogs, and forums. Therefore, the disseminators or organizations of Shanxi's red culture can try to learn from these forms and give full play to their characteristics. For example, you can set up a public platform about Red Shanxi on Weibo and forums to update the content in time for the audience to understand and learn. Forums and blogs mainly design some meaningful discussion topics on a regular basis. In addition to the red historical facts and red figures in Shanxi, the content of the discussion can also select current hot topics related to them. In the interaction, netizens' comments are inappropriate, and blogging mainly regulates and guides them in a timely manner. In addition, in the process of using new forms such as Weibo and podcasts, it is necessary to pay attention to the interactivity of interactive images, and to allow more netizens to participate in the dissemination, not limited to a few communicators or elites such as moderators and bloggers.

\subsection{Adopting interactive video animation to enhance the influence of Shanxi's red culture.}

Interactive video animation, with its lively, humorous, entertaining features and advanced communication methods, has firmly attracted the attention of a large number of viewers, especially young people. It is not only a cultural form in itself, but also a good platform for the spread of culture. If the characteristics of interactive video animation can be used scientifically and integrated with the red culture, it will play an important role in promoting the spread and education of the red culture in Shanxi.

First, strengthen the application of advanced technologies such as multimedia and the Internet in the animation industry, and strive to create a red animation brand that can reflect the local characteristics of Shanxi. Shanxi is an important gathering place for red resources. In the revolutionary war years, the party led the people to compose a magnificent and inspiring red Three Jin scrolls on this red loess plateau in Shanxi, leaving behind a large number of precious poems. For this, we must further explore the red culture Refining the essence of it, and embedding the red culture into interactive video animation, with the help of the spirituality of red culture and the diversification of interactive video animation, we have developed a series of popular values that are popular among the people and reflect mainstream values. Spiritual and cultural products. In addition, various regions can use the Internet's advanced communication technology to concentrate on creating some revolutionary animation movies and TV series, or produce a series of red promotional films for tourists to watch. Second, we must innovate the content and form of red animation. Shanxi's red culture contains a large number of heroes, red dramas and songs, and unique artistic modeling language. These traditional red historical elements are combined with modern audio-visual technology and successfully applied to the production of interactive video animation. On the 
basis of human aesthetic appeal, he created a red cartoon image that is very popular among netizens.

\subsection{Make full use of interactive video games}

Online games are highly interactive and entertaining. Its biggest feature is to place players in unpredictable, rich and interesting story scenes, allowing players to experience the realistic effects of the real world in the illusory world. [7] In recent years, interactive video games with revolutionary themes have also appeared one after another. This type of game is based on the promotion of red culture, has a strong sense of patriotism and historical mission, and has a strong shocking effect. However, compared with foreign interactive video games based on World War I and World War II, there are relatively few interactive video games based on red culture in China. Therefore, we should make full use of the interactive entertainment characteristics and lifelike effects of online games, and integrate red culture into interactive video games. First of all, play the educational and entertaining characteristics of games on the basis of respecting history and defending peace. The settings of all aspects of the game must always run through the entire historical event, always full of patriotism and historical responsibility, and create a real and natural historical scene for people by reproducing great moments of war, so that they can relive the development process of the Communist Party of China. Experience the great significance of victory in war. At the same time, red online games also need to give full play to their interactive, entertainment and other characteristics, centering on the national spirit, local characteristics, and themes of the times, so that players can experience the fun of the game while interacting. Red online games can only be entertaining and entertaining only if they incorporate patriotism on the basis of a high degree of entertainment. [8] Otherwise, if you focus too much on indoctrination and preaching, without considering entertainment, it will be difficult to attract the attention of the audience, and it will be difficult to gain a foothold in the market. Second, we must pay attention to the industrial linkage of red online games. On the one hand, red online games can be combined with the red film and television industry to simulate the storylines, war scenes, and characters in film and television dramas, so that players feel immersive and complete various tasks under the guidance of the game. On the other hand, Shanxi has many beautiful and well-known old revolutionary areas, which have become tourist attractions for people to visit and exhibit. For this, red online games can consider cooperation with Shanxi's red tourism industry and set up similar scenes in the game.

\section{ConClusion}

With the continuous improvement of interactive projection technology, digital interactive images are more widely used in the dissemination of red culture. The diversification of its projection forms provides more possibilities for dissemination of red culture. However, it should be noted that while designers are pursuing cool vision, they must also strengthen the audience. In order to create a more immersive and experiential viewing mode. The 21st century is a digital age. The entertainment and participation of digital interactive images due to their real-time change of "interaction" is already a trend of new media art creation, and the red culture communication will be greatly developed in the future.

\section{REFERENCES}

1. Chen Jing. Research on the Design of Red Cultural Theme Pavilion under the Background of Media Fusion[J]. Fujian Tea, 2020(3).

2. Wan Qingsong. Research on the Dilemma and Countermeasures of Cultural Tourism Resources Communication under the Background of Smart Tourism[J]. Shanxi Agricultural Economics, 2020, No.273(09):44+46.

3. Liang Jun, Chen Lijiao. Digital Communication Strategy of Red Culture Based on Visual Reconstruction Theory[J]. Ideological Education Research, 2020.

4. Cao Yuejuan. A Study on the Impact of Red Cultural Tourist Service Quality Perception on Behavioral Willingness[J]. Tourism Science, 2020(3):94-102.

5. Wang Chunxia. The Function of Red Culture in the Modernization of National Governance[J]. Ideological Education Research, 2020(7).

6. Lan Xiaohong, Wang Jing, Li Mei. Development of Tourism Cultural and Creative Products from the Perspective of Tourist Perception-Taking Datong City, Shanxi Province as an Example[J]. Journal of the Party School of Shanxi Provincial Committee of the Communist Party of China, 2020, 043(001):122125 .

7. Guo Yulan. The construction of a strong cultural tourism province under the background of global tourism-Taking Shanxi Province as an example[J]. Journal of the Party School of Shanxi Provincial Committee of the Communist Party of China, 2019, 042(005):65-69.

8. Luo Jingting. Research on the Interactive Mechanism of Interactive Images from the Perspective of Cybertext[J]. Journal of Beijing Film Academy, 2020(6).

9. Wan Xiuli, Wang Xin. Nourish the Party's Original Aspiration and Mission with Red Culture[J]. Journal of the Party School of Shanxi Provincial Committee of the Communist Party of China, 2020, 043(002):119-122. 